\title{
The visible spectrum of zirconium dioxide, $\mathrm{ZrO}_{2}$
}

Anh Le, Timothy C. Steimle', Varun Gupta, Corey A. Rice, John P. Maier, Sheng H. Lin, and Chih-Kai Lin

Citation: The Journal of Chemical Physics 135, 104303 (2011); doi: 10.1063/1.3632053

View online: http://dx.doi.org/10.1063/1.3632053

View Table of Contents: http://aip.scitation.org/toc/jcp/135/10

Published by the American Institute of Physics

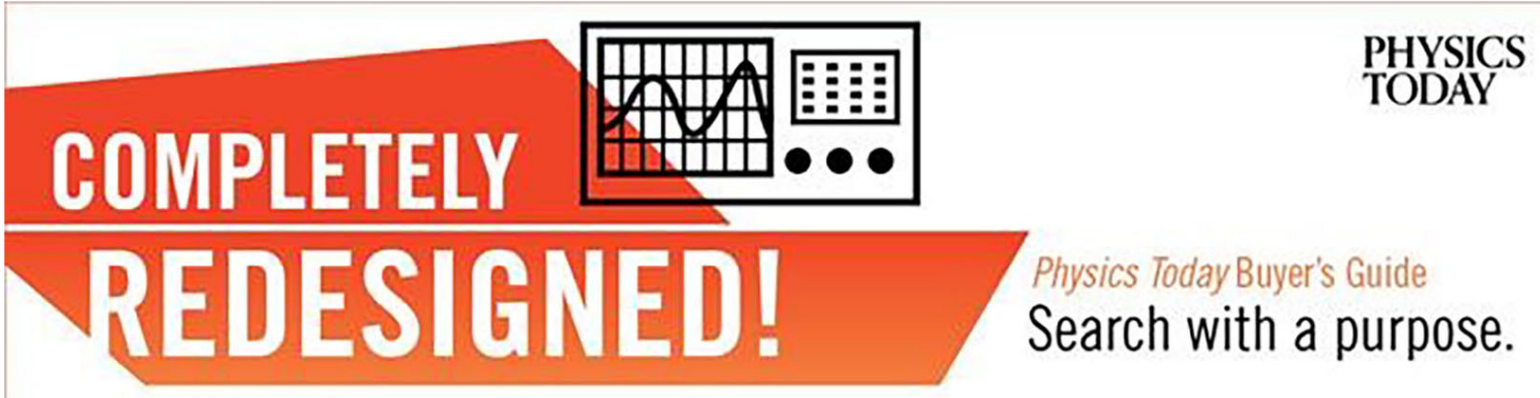




\title{
The visible spectrum of zirconium dioxide, $\mathrm{ZrO}_{2}$
}

\author{
Anh Le, ${ }^{1}$ Timothy C. Steimle, ${ }^{1, a)}$ Varun Gupta, ${ }^{2}$ Corey A. Rice, ${ }^{2}$ John P. Maier, ${ }^{2}$ \\ Sheng H. Lin, ${ }^{3}$ and Chih-Kai Lin ${ }^{3}$ \\ ${ }^{1}$ Department of Chemistry and Biochemistry, Arizona State University, Tempe, Arizona 85287-1604, USA \\ ${ }^{2}$ Department of Chemistry, University of Basel, Basel, Switzerland \\ ${ }^{3}$ Department of Applied Chemistry, National Chiao Tung University, Hsinchu, Taiwan
}

(Received 8 July 2011; accepted 12 August 2011; published online 8 September 2011)

\begin{abstract}
The electronic spectrum of a cold molecular beam of zirconium dioxide, $\mathrm{ZrO}_{2}$, has been investigated using laser induced fluorescence (LIF) in the region from $17000 \mathrm{~cm}^{-1}$ to $18800 \mathrm{~cm}^{-1}$ and by massresolved resonance enhanced multi-photon ionization (REMPI) spectroscopy from $17000 \mathrm{~cm}^{-1}$ $21000 \mathrm{~cm}^{-1}$. The LIF and REMPI spectra are assigned to progressions in the $\tilde{A}^{1} B_{2}\left(v_{1}, v_{2}, v_{3}\right)$ $\leftarrow \tilde{X}^{1} A_{1}(0,0,0)$ transitions. Dispersed fluorescence from 13 bands was recorded and analyzed to produce harmonic vibrational parameters for the $\tilde{X}^{1} A_{1}$ state of $\omega_{1}=898(1) \mathrm{cm}^{-1}, \omega_{2}=287(2)$ $\mathrm{cm}^{-1}$, and $\omega_{3}=808(3) \mathrm{cm}^{-1}$. The observed transition frequencies of 45 bands in the LIF and REMPI spectra produce origin and harmonic vibrational parameters for the $\tilde{A}^{1} B_{2}$ state of $T_{\mathrm{e}}=16307(8)$ $\mathrm{cm}^{-1}, \omega_{1}=819(3) \mathrm{cm}^{-1}, \omega_{2}=149(3) \mathrm{cm}^{-1}$, and $\omega_{3}=518(4) \mathrm{cm}^{-1}$. The spectra were modeled using a normal coordinate analysis and Franck-Condon factor predictions. The structures, harmonic vibrational frequencies, and the potential energies as a function of bending angle for the $\tilde{A}^{1} B_{2}$ and $\tilde{X}^{1} A_{1}$ states are predicted using time-dependent density functional theory, complete active space selfconsistent field, and related first-principle calculations. A comparison with isovalent $\mathrm{TiO}_{2}$ is made. (C) 2011 American Institute of Physics. [doi:10.1063/1.3632053]
\end{abstract}

\section{INTRODUCTION}

The metal-oxygen bond is of relevance in numerous chemical and biological processes. Insight into these phenomena can be effectively garnered by studying isolated gas-phase metal oxides for which both experimentation and theory can be quantitative. A perusal of the recent review ${ }^{1}$ reveals that spectroscopic and theoretical studies of transition metal dioxides are sparse in comparison to metal monoxides. Given the technological importance of titania, it is understandable that gas-phase $\mathrm{TiO}_{2}$ is amongst the most thoroughly studied. Studies of isovalent $\mathrm{ZrO}_{2}$, the subject of the present investigation, are fewer. Theoretical studies for both $\mathrm{TiO}_{2}$ and $\mathrm{ZrO}_{2}$ greatly outnumber experimental studies due to difficulties of generation and detection of these ephemeral molecules. The dioxides can have one of three isomeric forms; (a) the inserted form, similar to $\mathrm{TiO}_{2}$, with a large apex angle, (b) a "T-Shaped" form with a small apex angle and an $\mathrm{O}-\mathrm{O}$ distance close to that of $\mathrm{O}_{2}$, and (c) a $\mathrm{M}-\mathrm{O}-\mathrm{O}$ superoxide form. Sometime ago, an electrostatic deflection experiment determined that that ground state $\mathrm{ZrO}_{2}$ had a permanent electric dipole moment, ${ }^{2}$ thus ruling out the linear $\mathrm{OZrO}$ structure. The infrared absorption spectra of an argon matrix isolated sample was recorded, ${ }^{3}$ and the observed isotopic shifts determined that the ground state structure is the inserted $C_{2 v}$ form. The $v_{1}\left(a_{1}\right)$ symmetric stretching frequency, $\omega_{1}$, and the $v_{3}\left(b_{2}\right)$ antisymmetric stretching frequency, $\omega_{3}$, were inferred to be $884.3 \mathrm{~cm}^{-1}$ and $818.0 \mathrm{~cm}^{-1}$, respectively. The isotopic dependence of $\omega_{3}$ was used to estimate the bond angle, $\theta$, of

\footnotetext{
a) Author to whom correspondence should be addressed. Electronic mail: tsteimle@ASU.edu. Tel.: (480) 965-3265.
}

$113^{\circ} \pm 5^{\circ}$. A simple self-consistent field ab initio calculation using an effective core potential supported the results. The ground state pure rotational spectra of all five isotopologues have been recorded and analyzed ${ }^{4}$ from which a bond length, $R_{\mathrm{Zr}-\mathrm{O}}$, of $1.7710 \pm 0.0007 \AA$ and a $\mathrm{O}-\mathrm{Zr}-\mathrm{O}$ bond angle, $\theta$, of $108.11 \pm 0.08^{\circ}$ were derived. In that same study the electric dipole moment, $\mu$, was determined to be $7.80 \pm 0.02 \mathrm{D}$ and the harmonic bending frequency, $\omega_{2}$, was estimated as 290 $\mathrm{cm}^{-1}$ from the inertial defect. The electronic structure of $\mathrm{ZrO}_{2}$ was also investigated by photoelectron spectroscopy (PES) of the anion, $\mathrm{ZrO}_{2}^{-}$. ${ }^{5,6}$ Progressions in the PES spectrum were analyzed to determine symmetric stretching frequency, $\omega_{1}$, of $887 \pm 40 \mathrm{~cm}^{-1}$ for the $\tilde{X}^{1} A_{1}$ state and an adiabatic electron affinity of $1.64 \pm 0.03 \mathrm{eV}$ for the neutral. The $355 \mathrm{~nm}$ radiation used was insufficient to probe the regions of low-lying excited states of the neutral. Ab initio calculations ${ }^{6}$ using a coupled cluster method with single, double, and non-iterative triple excitations $(\mathrm{CCSD}(\mathrm{T}))$ were performed in support of the PES results. $R_{\mathrm{Zr}-\mathrm{O}}$ and $\theta$ were predicted to be $1.797 \AA$ and $109.6^{\circ}$, respectively, and $\omega_{1}, \omega_{2}$, and $\omega_{3}$ of $887 \mathrm{~cm}^{-1}$, $281 \mathrm{~cm}^{-1}$, and $835 \mathrm{~cm}^{-1}$. In a separate study, high level $a b$ initio calculations were performed to model the $355 \mathrm{~nm}$ photodetachment spectrum. ${ }^{7}$ At the $\operatorname{CCSD}(\mathrm{T})$ level, the predicted $\omega_{1}, \omega_{2}$, and $\omega_{3}$ for $\tilde{X}^{1} A_{1}$ were $909 \mathrm{~cm}^{-1}, 278 \mathrm{~cm}^{-1}$, and $841 \mathrm{~cm}^{-1}$, respectively. More recently, various high-level $a b$ initio and density functional theory (DFT) predicted the properties of the $\tilde{X}^{1} A_{1}$ and the low-lying $\tilde{B}^{3} B_{2}$ states. $^{8}$ The $\operatorname{CCSD}(\mathrm{T})$ theory gave $R_{\mathrm{Zr}-\mathrm{O}}$ and $\theta$ values for the $\tilde{X}^{1} A_{1}$ which were $1.802 \AA$ and $109.7^{\circ}$, respectively, and the $\omega_{1}$ and $\omega_{3}$ of $924 \mathrm{~cm}^{-1}$ and $860 \mathrm{~cm}^{-1}$. The splitting between $\tilde{X}^{1} A_{1}$ and $\tilde{B}^{3} B_{2}$ states varied from $1.82 \mathrm{eV}$ to $2.33 \mathrm{eV}$ depending upon the method employed. The equation-of-motion (EOM) at the 
EOM-CCDS level gave a separation of $2.14 \mathrm{eV}$. There are no predictions for the $\tilde{A}^{1} B_{2}$ state.

Here, we report on the first detection of the electronic transition for $\mathrm{ZrO}_{2}$. The electronic spectrum has been recorded using laser induced fluorescence (LIF) detection in the region from $17000 \mathrm{~cm}^{-1}$ to $18800 \mathrm{~cm}^{-1}$ and by massresolved resonance enhanced multi-photoionization (REMPI) spectroscopy from $17000 \mathrm{~cm}^{-1}$ to $21000 \mathrm{~cm}^{-1}$. This is a continuation of our studies of Group IVA metal dioxides. ${ }^{9}, 10$ The electronic spectra are modeled using multi-dimensional Franck-Condon factors (FCFs). An ab initio prediction is also performed.

\section{EXPERIMENT}

The experimental set-ups for the mass selected resonant enhanced multi-photon ionization (MS-REMPI), LIF, dispersed laser induced fluorescence (DLIF), and radiative lifetime measurements were nearly identical to those of the previous study of $\mathrm{TiO}_{2}{ }^{9}{ }^{9} 10$ The MS-REMPI measurements were carried out at the University of Basel (UB) using the spectrometer previously described. ${ }^{11}$ The LIF, DLIF, and lifetime measurements were performed at the Arizona State University (ASU). In all experiments $\mathrm{ZrO}_{2}$ was produced by laser ablation of a pure zirconium rod in the presence of a supersonic expanding mixture of $\sim 5 \% \mathrm{O}_{2}$ in either argon (ASU) or helium (UB). The supersonic expansion products were skimmed to produce a well collimated molecular beam. In the lowresolution $(\Delta v= \pm 90 \mathrm{GHz})$, REMPI experiment ions were removed by applying an electric potential on the skimmer before the molecular beam enters the ionization region of a Wiley-McLaren time-of-flight mass spectrometer. ${ }^{12}$ Neutral molecules were irradiated with a pulse of tunable photons from an optical parametric oscillator system (excitation laser) followed by $7.9 \mathrm{eV}(\lambda=157 \mathrm{~nm})$ photons from an $\mathrm{F}_{2}$ excimer laser (ionization laser). Ions were extracted into a timeof-flight tube where the signal from a microchannel plate ion detector was sent to a fast oscilloscope and data acquisition card. The combination of the tunable and $7.9 \mathrm{eV}$ photons was sufficient to ionize $\mathrm{ZrO}_{2}$, exceeding the ionization potential of $9.4 \mathrm{eV}^{13}$

In the LIF, DLIF, and lifetime measurements the supersonic free-jet expansion was probed $10 \mathrm{~cm}$ from the source with an excimer pumped pulsed dye laser, having a linewidth of $\sim 0.1 \mathrm{~cm}^{-1}$. The laser frequency was calibrated by recording the neon optogalvanic spectrum. In the LIF excitation and radiative lifetime measurements, the fluorescence was viewed off resonance through a $650 \mathrm{~nm}$ long-pass filter and was detected with a cooled photomultiplier tube and processed with a box-car integrator. The radiative lifetimes were measured using the same set-up but with the LIF signal recorded on a digital storage oscilloscope. The DLIF spectra were recorded by tuning the wavelength of the pulsed dye laser to excite the most intense feature of each band and viewing the LIF signal through a $2 / 3 \mathrm{~m}$ scanning monochromator. The slit widths were adjusted to produce a spectral linewidth FWHM - of $\sim 20 \AA$. The signal was detected using a cooled photomultiplier tube and processed using gated photon counting.

\section{COMPUTATIONAL DETAILS}

Several first-principle computational approaches have been applied to calculate the properties of the ${ }^{90} \mathrm{Zr}^{16} \mathrm{O}_{2}$ monomer. For the structural optimization and vibrational frequency calculation of the $\tilde{X}^{1} A_{1}$ state, two categories of computations were applied: (1) DFT with the B3LYP functional and (2) complete active space self-consistent field (CASSCF), and CASSCF with the second-order perturbation (CASPT2) for the treatment of dynamical electron correlation. For the two lowest singlet excited states $\left(\tilde{A}^{1} B_{2}\right.$ and $\tilde{B}^{1} A_{1}$ ), time-dependent density functional theory (TDDFT) and complete active space (CAS) procedures were applied to determine vertical and adiabatic energy gaps and geometries. In the CAS procedures, all valence electrons and orbitals except the innermost ones composed of the $\mathrm{O}(2 s)$ atomic orbitals were selected, forming the $(12,12)$ active space. The Los Alamos effective core potential (ECP) plus double-zeta (LanL2DZ) (Ref. 14) basis set were employed, and the Stevens, Basch, Krauss and Jasien effective core potentials (SBKJ ECP) (Refs. 15 and 16) were also used for comparison.

Systematic scans on the potential energy surfaces (PES) were performed by varying the geometry of the molecule. In the one-dimensional PES scan (cf. Ref. 17), the O-Zr$\mathrm{O}$ bending angle was varied from $40^{\circ}$ to $180^{\circ}$ by a step of $5^{\circ}$, followed by a partial geometry optimization and excited state calculation at each fixed angle. TD-DFT was applied in these scans to describe up to five singlet excited states. All the DFT and CAS calculations were performed with GAUSSIAN 09 (Ref. 18) and MOLPRO 2006 (Ref. 19) computational packages, respectively.

\section{OBSERVATION}

There are five stable isotopes of zirconium: ${ }^{90} \mathrm{Zr}(51.5 \%)$, ${ }^{91} \operatorname{Zr}(11.2 \%),{ }^{92} \operatorname{Zr}(17.2 \%),{ }^{94} \operatorname{Zr}(17.4 \%)$, and ${ }^{96} \operatorname{Zr}(2.8 \%)$. The MS-REMPI spectrum of ${ }^{90} \mathrm{ZrO}_{2}$ in the $17000 \mathrm{~cm}^{-1}-21000$ $\mathrm{cm}^{-1}$ region and the LIF spectrum of the ablation products in the $17000 \mathrm{~cm}^{-1}-18800 \mathrm{~cm}^{-1}$ region are presented in Figure 1. Based upon the analogy with $\mathrm{TiO}_{2},{ }^{9,10}$ the spectral simulation, and the $a b$ initio prediction (vide infra), the spectra are assigned to progressions in the $\tilde{A}^{1} B_{2}\left(v_{1}, v_{2}, v_{3}\right)$ $\leftarrow \tilde{X}^{1} A_{1}(0,0,0)$ transition. The relative intensities of the bands in the LIF spectrum are nearly identical to those for the MS-REMPI spectrum. The band marked with an "*" in the LIF spectrum is the $C^{1} \Sigma^{+}-X^{1} \Sigma^{+}(1,0)$ transition of $\mathrm{ZrO}$. The $C^{1} \Sigma^{+}-X^{1} \Sigma^{+}(0,0)$ transition of $\mathrm{ZrO}$ overlaps the $\tilde{A}^{1} B_{2}(0,0$, $0) \leftarrow \tilde{X}^{1} A_{1}(0,0,0)$ band of $\mathrm{ZrO}_{2}$. The $\mathrm{ZrO}$ spectral features can be suppressed relative to those for $\mathrm{ZrO}_{2}$ by adjusting the production conditions and by using a long gate time $(\approx 1 \mu \mathrm{s})$ on the box car integrator. The lifetime of the $C^{1} \Sigma^{+}-$ $X^{1} \Sigma^{+}$transition of $\mathrm{ZrO}$ is $\sim 130 \mathrm{~ns},{ }^{20}$ whereas the lifetimes for the bands of $\mathrm{ZrO}_{2}$ are much longer (vide infra). There are no features to the red of the band at $17041 \mathrm{~cm}^{-1}$, so it was assigned to the $\tilde{A}^{1} B_{2}(0,0,0) \leftarrow \tilde{X}^{1} A_{1}(0,0,0)$ transition, assuming adiabatic expansion conditions and that only the $\tilde{X}^{1} A_{1}(0,0,0)$ level is populated. The assignments, transition wavenumber, difference between the observed transition 

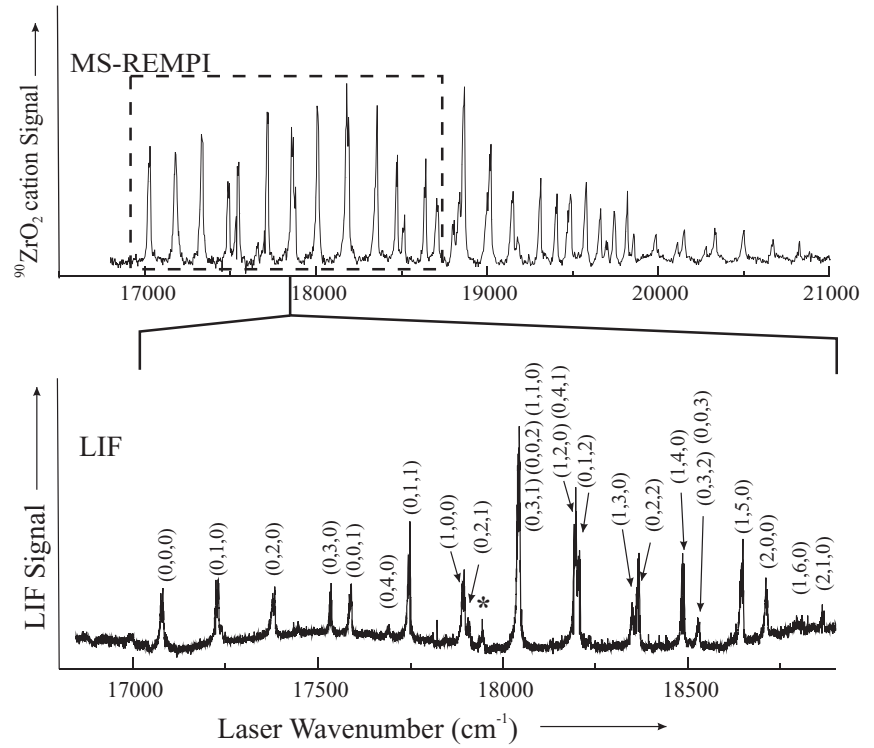

FIG. 1. Mass selected resonance enhanced multiphoton ionization (MSREMPI) spectrum (top) and laser induced fluorescence (LIF) spectrum (bottom) of $\tilde{A}^{1} B_{2}\left(v_{1}, v_{2}, v_{3}\right) \leftarrow \tilde{X}^{1} A_{1}(0,0,0)$ transition of $\mathrm{ZrO}_{2}$. The spectral feature marked with "**" is the $C^{1} \Sigma^{+}-X^{1} \Sigma^{+}(1,0)$ transition of $\mathrm{ZrO}$. The $C^{1} \Sigma^{+}-X^{1} \Sigma^{+}(0,0)$ transition of $\mathrm{ZrO}$ overlaps the $\tilde{A}^{1} B_{2}(0,0,0)$ $\leftarrow \tilde{X}^{1} A_{1}(0,0,0)$ band of $\mathrm{ZrO}_{2}$.

wavenumbers and those calculated using the optimized parameters, and the predicted Franck-Condon factors are given in Table I.

The DLIF spectra resulting from the excitation of the 13 bands observed via LIF were recorded. In all cases no features to the blue of the excitation wavelength were observed, confirming that the lower level associated with the LIF spectra is the $\tilde{X}^{1} A_{1}(0,0,0)$ state. DLIF spectra resulting from the excitation of the $\tilde{A}^{1} B_{2}(0,0,0) \leftarrow \tilde{X}^{1} A_{1}(0,0,0)\left(17041 \mathrm{~cm}^{-1}\right)$, $\tilde{A}^{1} B_{2}(0,0,1) \leftarrow \tilde{X}^{1} A_{1}(0,0,0)\left(17562 \mathrm{~cm}^{-1}\right)$, and $\tilde{A}^{1} B_{2}$ $(1,0,0) \leftarrow \tilde{X}^{1} A_{1}(0,0,0)\left(17870 \mathrm{~cm}^{-1}\right)$ bands are presented in Figure 2. Similar to $\mathrm{TiO}_{2},{ }^{10}$ long progressions in the bending $v_{2}\left(a_{1}\right)$ mode (e.g., Figure $2\left(\right.$ a) $\tilde{A}^{1} B_{2}(0,0,0) \rightarrow \tilde{X}^{1} A_{1}(0$, $\left.v_{2}, 0\right)$ ) and symmetric stretch $v_{1}\left(a_{1}\right)$ mode (e.g., Figure 2(b) $\left.\tilde{A}^{1} B_{2}(1,0,0) \rightarrow \tilde{X}^{1} A_{1}\left(v_{1}, 0,0\right)\right)$ and combinations of $v_{1}\left(a_{1}\right)$ and $v_{2}\left(a_{1}\right)$ modes (e.g., Figure $2\left(\right.$ a) $\tilde{A}^{1} B_{2}(0,0,0) \rightarrow \tilde{X}^{1} A_{1}$ $\left.\left(v_{1}, v_{2}, 0\right)\right)$ are observed. Unlike $\mathrm{TiO}_{2},{ }^{10}$ long progressions in the antisymmetric $v_{3}\left(b_{2}\right)$ mode (e.g., Figure $2(\mathrm{c}) \tilde{A}^{1} B_{2}(0,0$, $\left.1) \rightarrow \tilde{X}^{1} A_{1}\left(0,0, v_{3}\right)\right)$ and combinations of $v_{3}\left(b_{2}\right)$ and $v_{2}\left(a_{1}\right)$ modes (e.g., Figures 2(b) and 2(c) $\tilde{A}^{1} B_{2}(0,0,1) \rightarrow \tilde{X}^{1} A_{1}(0$, $\left.v_{2}, v_{3}\right)$ ) are observed. A total of 268 features for the 13 DLIF spectra were assigned and positions were measured. The transition wavenumber, assignments, and the difference between the observed shifts and those calculated using the optimized parameters are available via the supplementary material or through the author (T.C.S.). ${ }^{21}$

Fluorescence decay curves of the 13 bands observed in the LIF spectrum were recorded. The curves resulting from the excitation of the $\tilde{A}^{1} B_{2}(0,0,0) \leftarrow \tilde{X}^{1} A_{1}(0,0,0)$ band at $17041 \mathrm{~cm}^{-1}$ and $\tilde{A}^{1} B_{2}(0,0,1) \leftarrow \tilde{X}^{1} A_{1}(0,0,0)$ band at $17562 \mathrm{~cm}^{-1}$ are presented in Figure 3. The curves exhibit single exponential dependence with the $\tilde{A}^{1} B_{2}(0,0,0)$ lifetime being significantly shorter than that of $\tilde{A}^{1} B_{2}(0,0,1)$ state.
TABLE I. Observed and calculated band maxima $\left(\mathrm{cm}^{-1}\right)$ for the $\tilde{A}^{1} B_{2}$ $\leftarrow \tilde{X}^{1} A_{1}$ electronic transition of $\mathrm{ZrO}_{2}$.

\begin{tabular}{|c|c|c|c|}
\hline $\begin{array}{l}\text { Assignment } \\
\left(v_{1}, v_{2}, v_{3}\right)\end{array}$ & $\begin{array}{l}\text { Observed } \\
\left(\mathrm{cm}^{-1}\right)\end{array}$ & $\begin{array}{l}\text { Obs.-calc. } \\
\left(\mathrm{cm}^{-1}\right)\end{array}$ & FCF \\
\hline$(0,0,0)$ & 17041 & -9 & $5.01 \times 10^{-2}$ \\
\hline$(0,1,0)$ & 17194 & -9 & $1.34 \times 10^{-1}$ \\
\hline$(0,2,0)$ & 17351 & -4 & $1.28 \times 10^{-1}$ \\
\hline$(0,3,0)$ & 17506 & -1 & $4.75 \times 10^{-2}$ \\
\hline$(0,0,1)$ & 17562 & 8 & $5.06 \times 10^{-2}$ \\
\hline$(0,4,0)$ & 17663 & 4 & $2.86 \times 10^{-3}$ \\
\hline$(0,1,1)$ & 17723 & 12 & $1.35 \times 10^{-1}$ \\
\hline$(1,0,0)$ & 17873 & 4 & $6.48 \times 10^{-2}$ \\
\hline$(0,2,1)$ & 17888 & 20 & $1.30 \times 10^{-1}$ \\
\hline$(0,0,2)$ & 18026 & -16 & $4.79 \times 10^{-2}$ \\
\hline$(0,3,1)$ & 18026 & 1 & $1.42 \times 10^{-1}$ \\
\hline$(1,1,0)$ & 18026 & 1 & $1.20 \times 10^{-3}$ \\
\hline$(1,2,0)$ & 18181 & 2 & $2.89 \times 10^{-3}$ \\
\hline$(0,4,1)$ & 18181 & 0 & $1.02 \times 10^{-1}$ \\
\hline$(0,1,2)$ & 18193 & -9 & $3.19 \times 10^{-3}$ \\
\hline$(1,3,0)$ & 18336 & 2 & $2.02 \times 10^{-2}$ \\
\hline$(0,2,2)$ & 18357 & -7 & $3.07 \times 10^{-3}$ \\
\hline$(1,4,0)$ & 18476 & -14 & $1.83 \times 10^{-4}$ \\
\hline$(0,0,3)$ & 18518 & 7 & $1.14 \times 10^{-3}$ \\
\hline$(0,3,2)$ & 18518 & -7 & $3.63 \times 10^{-3}$ \\
\hline$(1,5,0)$ & 18643 & -2 & $4.21 \times 10^{-3}$ \\
\hline$(2,0,0)$ & 18706 & 18 & $4.49 \times 10^{-2}$ \\
\hline$(1,6,0)$ & 18806 & 6 & $2.08 \times 10^{-3}$ \\
\hline$(2,1,0)$ & 18863 & 17 & $8.10 \times 10^{-2}$ \\
\hline$(2,2,0)$ & 19020 & 16 & $4.16 \times 10^{-2}$ \\
\hline$(2,3,0)$ & 19173 & 11 & $2.99 \times 10^{-3}$ \\
\hline$(2,0,1)$ & 19173 & -19 & $4.54 \times 10^{-2}$ \\
\hline$(2,4,0)$ & 19310 & -10 & $1.88 \times 10^{-3}$ \\
\hline$(0,0,5)$ & 19404 & 6 & $2.17 \times 10^{-4}$ \\
\hline$(3,0,0)$ & 19484 & -23 & $2.21 \times 10^{-2}$ \\
\hline$(0,1,5)$ & 19575 & 3 & $5.77 \times 10^{-4}$ \\
\hline$(3,1,0)$ & 19660 & -8 & $3.25 \times 10^{-2}$ \\
\hline$(2,0,2)$ & 19691 & 12 & $1.07 \times 10^{-3}$ \\
\hline$(0,2,5)$ & 19738 & -9 & $5.55 \times 10^{-4}$ \\
\hline$(3,2,0)$ & 19816 & -12 & $1.13 \times 10^{-2}$ \\
\hline$(2,1,2)$ & 19851 & 5 & $1.94 \times 10^{-3}$ \\
\hline$(0,3,5)$ & 19907 & -14 & $2.05 \times 10^{-4}$ \\
\hline$(3,3,0)$ & 19982 & -7 & $4.19 \times 10^{-5}$ \\
\hline$(0,4,5)$ & 20107 & 11 & $1.24 \times 10^{-5}$ \\
\hline$(3,4,0)$ & 20147 & -3 & $1.58 \times 10^{-3}$ \\
\hline$(0,5,5)$ & 20274 & 4 & $6.61 \times 10^{-5}$ \\
\hline$(4,0,0)$ & 20323 & -2 & $8.67 \times 10^{-3}$ \\
\hline$(4,1,0)$ & 20494 & 5 & $1.02 \times 10^{-2}$ \\
\hline$(4,2,0)$ & 20663 & 10 & $2.21 \times 10^{-3}$ \\
\hline$(4,3,0)$ & 20819 & 2 & $9.67 \times 10^{-5}$ \\
\hline Std. dev. $=9.64 \mathrm{~cm}^{-1}$ & & & \\
\hline
\end{tabular}

\section{ANALYSIS}

The observed 268 spectral features in the DLIF (Ref. 21) spectra were fit using the phenomenological expression: ${ }^{22}$

$$
\begin{aligned}
G\left(v_{1}, v_{2}, v_{3}\right)= & T_{e}+\sum_{i=1 \rightarrow 3} \omega_{i}\left(v_{i}+\frac{1}{2}\right) \\
& +\sum_{i=1 \rightarrow 3} \sum_{k=1 \rightarrow 3} \chi_{i k}\left(v_{i}+\frac{1}{2}\right)\left(v_{k}+\frac{1}{2}\right) .
\end{aligned}
$$




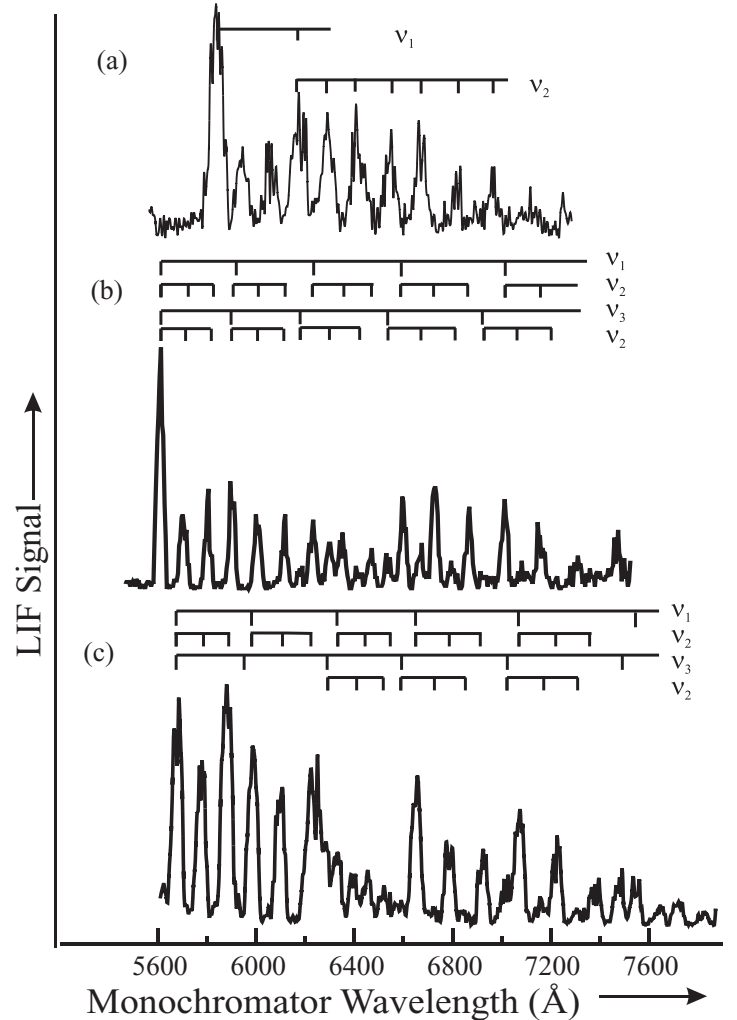

FIG. 2. Dispersed laser induced fluorescence (DLIF) spectra resulting from the excitation of: (a) the $\tilde{A}^{1} B_{2}(0,0,0) \leftarrow \tilde{X}^{1} A_{1}(0,0,0)$ band at 17041 $\mathrm{cm}^{-1}$; (b) the $\tilde{A}^{1} B_{2}(0,0,1) \leftarrow \tilde{X}^{1} A_{1}(0,0,0)$ band at $17562 \mathrm{~cm}^{-1}$; and (c) the $\tilde{A}^{1} B_{2}(1,0,0) \leftarrow \tilde{X}^{1} A_{1}(0,0,0)$ band at $17870 \mathrm{~cm}^{-1}$.

Various combinations of the anharmonic parameters, $\chi_{i k}$, were attempted. In the end, the DLIF data set could be satisfactorily fit by varying only $\chi_{22}$ and $\chi_{33}$ in addition to $\omega_{1}, \omega_{2}$, and $\omega_{3}$ for the $\tilde{X}^{1} A_{1}$ state. The optimized vibrational parameters and their errors are presented in Table II. The standard deviation of the fit $\left(\sigma=9.45 \mathrm{~cm}^{-1}\right)$ is commensurate with estimated measurement uncertainty of the DLIF.

Forty spectral features of the excitation spectra were assigned to 45 transitions and fit using Eq. (1). The 20 LIF features of this data set were assigned a weight three times that of the 20 lower resolution MS-REMPI spectral features. Only the more precisely measured LIF spectral features were included for transitions that were measured both by MS-REMPI and LIF. Various combinations of the anharmonic terms were attempted. In the end, a fit of the excitation spectra was obtained by varying only $\chi_{12}, \chi_{23}$, and $\chi_{33}$ in addition to $\omega_{1}$, $\omega_{2}$, and $\omega_{3}$ for the $\tilde{A}^{1} B_{2}$ state. The standard deviation of the fit $\left(\sigma=9.64 \mathrm{~cm}^{-1}\right)$ is commensurate with estimated combined measurement uncertainty of the LIF and MS-REMPI spectra. The optimized vibrational parameters for the $\tilde{A}^{1} B_{2}$ state and associated errors are presented in Table II.

The LIF decay curves were fit using a non-linear least square method to the single exponential decay model:

$$
Y=Y_{0}+A e^{\frac{-\left(t+t_{0}\right)}{\tau}},
$$

where $t_{0}$ was fixed to a time after the detection system had recovered from the initial laser scatter (typically $20 \mathrm{~ns}$ ). De-

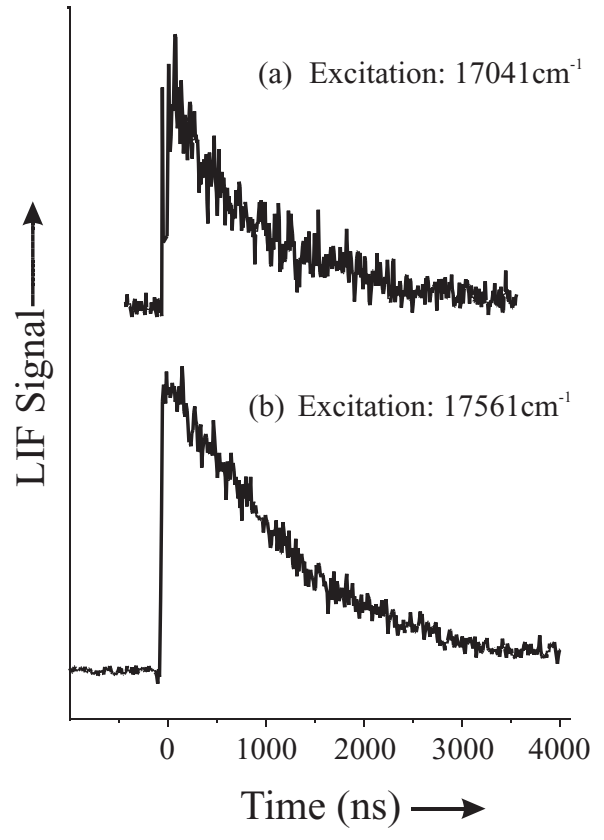

FIG. 3. Fluorescent decay curves resulting from excitation of: (a) the $\tilde{A}^{1} B_{2}(0,0,0) \leftarrow \tilde{X}^{1} A_{1}(0,0,0)$ band at $17041 \mathrm{~cm}^{-1}$ and (b) the $\tilde{A}^{1} B_{2}(0$, $0,1) \leftarrow \tilde{X}^{1} A_{1}(0,0,0)$ band at $17562 \mathrm{~cm}^{-1}$. The radiative lifetime of the $\tilde{A}^{1} B_{2}(0,0,0)$ state is less than that for the $\tilde{A}^{1} B_{2}(0,0,1)$.

cay curves obtained in the absence of molecules were also recorded and subtracted form those recorded in the presence of the molecules to enhance the signal-to-noise. Time greater than $4 \mu$ s was neglected because the molecules drift out of the LIF collection region. The determined lifetimes and associated errors are presented in Table III.

\section{DISCUSSION}

The determined $\omega_{1}\left(898 \pm 1 \mathrm{~cm}^{-1}\right)$ and $\omega_{3}(808 \pm 3$ $\mathrm{cm}^{-1}$ ) values for the $\tilde{X}^{1} A_{1}$ state are similar to $884.3 \mathrm{~cm}^{-1}$ and $818 \mathrm{~cm}^{-1}$ derived from the analysis of the infrared spectrum of a matrix isolated sample $\mathrm{e}^{3}$ and $887 \pm 40 \mathrm{~cm}^{-1}$ extracted from the PES spectrum. ${ }^{6}$ The $\omega_{2}\left(287 \pm 2 \mathrm{~cm}^{-1}\right)$ is also consistent with the $290 \mathrm{~cm}^{-1}$ value estimated from the inertial defect. ${ }^{4}$ As expected, $\omega_{1}$ and $\omega_{2}$ for the $\tilde{X}^{1} A_{1}$ state of $\mathrm{ZrO}_{2}$ are slightly less than $\omega_{1}\left(968 \pm 7 \mathrm{~cm}^{-1}\right)$ and $\omega_{2}$

TABLE II. Vibrational constants for the ground $\left(\tilde{X}^{1} A_{1}\right)$ and excited $\left(\tilde{A}^{1} B_{2}\right)$ states of $\mathrm{ZrO}_{2}$.

\begin{tabular}{lccc}
\hline \hline $\begin{array}{l}\tilde{X}^{1} A_{1} \\
\text { Parameter }\end{array}$ & $\begin{array}{c}\tilde{A}^{1} B_{2} \\
\text { Value } \\
\left(\mathrm{cm}^{-1}\right)\end{array}$ & Parameter & $\begin{array}{c}\text { Value } \\
\left(\mathrm{cm}^{-1}\right)\end{array}$ \\
\hline$\omega_{1}$ & $898(1)$ & $T_{\mathrm{e}}$ & $16307(8)$ \\
$\omega_{2}$ & $287(2)$ & $\omega_{1}$ & $819(3)$ \\
$\omega_{2}$ & $808(3)$ & $\omega_{2}$ & $149(3)$ \\
$\chi_{33}$ & $9.86(52)$ & $\omega_{3}$ & $518(4)$ \\
$\chi_{22}$ & $3.52(48)$ & $\chi_{12}$ & $2(1)$ \\
& & $\chi_{23}$ & $4.43(75)$ \\
& & $\chi_{33}$ & $-8.50(78)$ \\
\hline \hline
\end{tabular}


TABLE III. Florescence lifetimes for the $\tilde{A}^{1} B_{2}\left(v_{1}, v_{2}, v_{3}\right)$ states of $\mathrm{ZrO}_{2}$.

\begin{tabular}{lcc}
\hline \hline $\begin{array}{l}\text { Band } \\
\left(\mathrm{cm}^{-1}\right)\end{array}$ & $\left(\nu_{1}, \nu_{2}, \nu_{3}\right)$ & $\begin{array}{c}\text { Lifetime } \tau \\
(\mu \mathrm{s})\end{array}$ \\
\hline 17034.8 & $(000)$ & $0.900(32)$ \\
17189.68 & $(010)$ & $1.212(17)$ \\
17350.8 & $(020)$ & $1.095(59)$ \\
17506.01 & $(030)$ & $1.264(25)$ \\
17561 & $(001)$ & $1.391(28)$ \\
17723.38 & $(011)$ & $1.378(22)$ \\
17873.16 & $(001)$ & $1.128(18)$ \\
18025.73 & $(002)(031)(110)$ & $1.301(18)$ \\
18181.36 & $(120)(041)$ & $1.387(19)$ \\
18356.55 & $(022)$ & $1.373(39)$ \\
18476.25 & $(140)$ & $1.315(26)$ \\
18642.77 & $(150)$ & $1.227(30)$ \\
18710.05 & $(200)$ & $0.925(12)$ \\
\hline \hline
\end{tabular}

(323 $\left.\pm 1 \mathrm{~cm}^{-1}\right)$ for the lighter $\mathrm{TiO}_{2} \cdot{ }^{9,10}$ A comparison of $\omega_{3}\left(\tilde{X}^{1} A_{1}\right)$ is not possible because, unlike $\mathrm{ZrO}_{2}$, transitions involving $v_{3}\left(b_{2}\right)$ were not detected in the DLIF spectrum of $\mathrm{TiO}_{2}$. The determined $\omega_{1}, \omega_{2}$, and $\omega_{3}$ values for the $\tilde{A}^{1} B_{2}$ state are $819 \pm 3 \mathrm{~cm}^{-1}, 149 \pm 3 \mathrm{~cm}^{-1}$, and $518 \pm 4 \mathrm{~cm}^{-1}$, respectively, whereas the corresponding values for $\mathrm{TiO}_{2}$ are $876 \pm 3 \mathrm{~cm}^{-1}, 184 \pm 1 \mathrm{~cm}^{-1}$, and $316 \pm 2 \mathrm{~cm}^{-1}$. There is a large reduction in $\omega_{2}$ and $\omega_{3}$ upon excitation to the $\tilde{A}^{1} B_{2}$ state for both molecules.

The determined harmonic vibrational frequencies $\left(\omega_{1}\right.$, $\omega_{2}$, and $\omega_{3}$ ), structure $\left(R\right.$ and $\theta$ ), and term energies, $T_{\mathrm{e}}$, for the $\tilde{X}^{1} A_{1}$ and $\tilde{A}^{1} B_{2}$ states are compared with predicted values in Table IV. For the $\tilde{X}^{1} A_{1}$ state, the computational methods overestimated the $\mathrm{Zr}-\mathrm{O}$ bond length by up to $0.08 \AA$, while the $\mathrm{O}-\mathrm{Zr}-\mathrm{O}$ angle is rather insensitive to methodology and consistent with experiment. The vibrational frequencies and permanent dipole moment are slightly overestimated, typical of these calculations. ${ }^{6,7}$ Although the term energy of the $\tilde{A}^{1} B_{2}$ state is accurately predicted using TD-DFT, the values for $\omega_{2}$ and $\omega_{3}$ are in poor agreement with observations. The calculated $T_{\mathrm{e}}, \omega_{1}, \omega_{2}$, and $\omega_{3}$ at the CASSCF/LanL2DZ level of theory are also in poor agreement with the experiment. The imaginary vibrational frequency for $v_{3}\left(b_{2}\right)$, predicted by the CASSCF method, implies that the "equilibrium" geometry is located on a potential saddle point. This is probably the top of the barrier of a double-well mode whose potential is distorted by the vibronic coupling with the higher neighboring $\tilde{B}^{1} A_{1}$ state. $^{23,24}$ The CASSCF/LanL2DZ equilibrium $R$ and $\theta$ of $1.884 \AA$ and $96.6^{\circ}$ differ significantly from the TDDFT/LanL2DZ values of $1.843 \AA$ and $101.8^{\circ}$. There is no direct experimental measurement of $R$ and $\theta$ for the $\tilde{A}^{1} B_{2}$, but the REMPI and LIF excitation spectra could be best modeled using $1.828 \AA$ and $99.0^{\circ}$ (vide infra), which are near the TD-DFT values.

The TD-DFT one dimension potential energy surfaces for the six lowest electronic states are presented in Figure 4. The potential minima of the ground and the lowest two singlet states occur between $100^{\circ}$ and $110^{\circ}$. In contrast to $\mathrm{TiO}_{2},{ }^{17}$ the $\tilde{C}^{1} A_{2}$ state of $\mathrm{ZrO}_{2}$ is located higher than the $\tilde{B}^{1} A_{1}$ state at the Franck-Condon point, and the order changes when the angle increases. In the linear configuration, the $\tilde{A}^{1} B_{2}$ and $\tilde{C}^{1} A_{2}$ states and the $\tilde{B}^{1} A_{1}$ and $\tilde{E}^{1} B_{1}$ states become degenerate and straddle becomes the non-degenerate $\tilde{D}^{1} B_{2}$ state. The energy ordering is that expected for the five $\mathrm{Zr}^{+2}(4 d)$ orbitals ligandfield split into $\delta, \sigma$, and $\pi$-orbitals by the two axial $\mathrm{O}^{-}$anions.

TABLE IV. Experimental and theoretical properties for $\tilde{X}^{1} A_{1}$ and $\tilde{A}^{1} B_{2}$ states of $\mathrm{ZrO}_{2}$.

\begin{tabular}{|c|c|c|c|c|c|c|c|}
\hline Method & $\begin{array}{c}R_{\mathrm{Zr}-\mathrm{O}} \\
(\AA)\end{array}$ & $\begin{array}{c}\theta_{\mathrm{O}-\mathrm{Zr}-\mathrm{O}} \\
\left(^{\circ}\right)\end{array}$ & $\begin{array}{c}T_{\mathrm{e}} \\
\left(\mathrm{cm}^{-1}\right)\end{array}$ & $\begin{array}{c}\omega_{1} \\
\left(a_{1}\right)\end{array}$ & $\begin{array}{c}\omega_{2} \\
\left(a_{1}\right)\end{array}$ & $\begin{array}{c}\omega_{3} \\
\left(b_{2}\right)\end{array}$ & $\begin{array}{c}\mu \\
\text { (D) }\end{array}$ \\
\hline \multicolumn{8}{|l|}{$\tilde{X}^{1} A_{1}$} \\
\hline Expt. & $1.771 \pm 0.0007^{\mathrm{a}}$ & $108.1 \pm 0.08^{\mathrm{a}}$ & & $898 \pm 1^{\mathrm{b}}$ & $287 \pm 2^{b}$ & $808 \pm 2^{b}$ & $7.80 \pm 0.02^{\mathrm{a}}$ \\
\hline$B 3 L Y P^{c}$ & 1.806 & 107.2 & & 915 & 303 & 870 & 8.02 \\
\hline B3LYPd & 1.806 & 108.0 & & 906 & 295 & 854 & 8.16 \\
\hline $\mathrm{CASSCF}^{\mathrm{c}}$ & 1.827 & 107.7 & & 882 & 291 & 835 & 8.39 \\
\hline CASPT2 $^{c}$ & 1.846 & 107.7 & & 833 & 282 & 802 & 8.27 \\
\hline $\operatorname{CCSD}(\mathrm{T})^{\mathrm{e}}$ & 1.797 & 109.6 & & 887 & 281 & 835 & \\
\hline $\operatorname{CCSD}(T)^{\mathrm{f}}$ & 1.7776 & 108.26 & & 909 & 278 & 841 & \\
\hline $\operatorname{CCSD}(\mathrm{T})^{\mathrm{g}}$ & 1.802 & 109.7 & & 924 & & 860 & \\
\hline \multicolumn{8}{|l|}{$\tilde{A}^{1} B_{2}$} \\
\hline Expt. $^{b}$ & $1.828^{\mathrm{h}}$ & $99.0^{\mathrm{h}}$ & $16307 \pm 8$ & $819 \pm 3$ & $149 \pm 3$ & $518 \pm 4$ & \\
\hline TD-B3LYP & 1.843 & 101.8 & 16753 & 855 & 181 & 420 & 4.42 \\
\hline TD-B3LYP ${ }^{d}$ & 1.842 & 104.0 & 16525 & 839 & 174 & 396 & 4.29 \\
\hline $\mathrm{CASSCF}^{\mathrm{c}}$ & 1.884 & 96.6 & 12586 & 794 & 182 & $350 i$ & 4.32 \\
\hline $\mathrm{CASPT}^{\mathrm{c}}$ & 1.902 & 97.3 & 13733 & $\ldots$ & $\ldots$ & $\ldots$ & 4.11 \\
\hline
\end{tabular}

${ }^{\mathrm{a}}$ Reference 4.

${ }^{\mathrm{b}}$ This work.

${ }^{\mathrm{c}}$ This work; calculated using the LanL2DZ basis set.

${ }^{\mathrm{d}}$ This work; calculated using the SBKJ basis set.

${ }^{\mathrm{e}}$ Reference 6.

${ }^{\mathrm{f}}$ Reference 7.

${ }^{\mathrm{g}}$ Reference 8 .

${ }^{\mathrm{h}}$ This work; determined from a comparison of the observed and predicted intensities. 


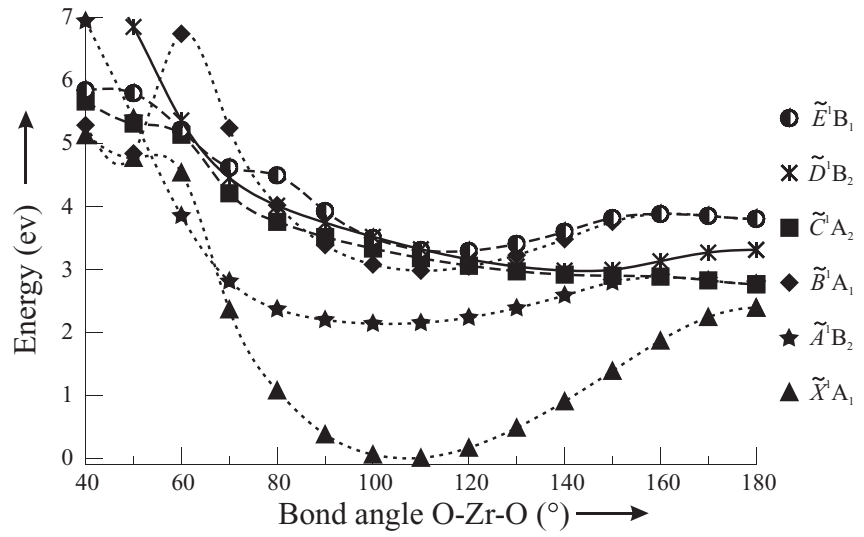

FIG. 4. One-dimensional potential energies for the six lowest electronic states as a function of bending angle obtained using TD-DFT with the B3LYP functional.

Insight into the bonding may be derived from the displacement vectors for the symmetric stretch $\left(Q_{1}\right)$, bend $\left(Q_{2}\right)$, and antisymmetric stretch $\left(Q_{3}\right)$ normal mode motion for the $\tilde{X}^{1} A_{1}$ and $\tilde{A}^{1} B_{2}$ states shown in Figure 5. The displacement vectors have all been doubled in length for illustrative purposes. The displacement vectors were obtained from a normal mode analysis using the Wilson $G F$ matrix approach, ${ }^{25}$ details of which are described in Appendix A. The experimental structure of $1.7710 \AA$ and $108.11^{\circ}$ for the $\tilde{X}^{1} A_{1}$ were taken from Ref. 4 . The structure for the $\tilde{A}^{1} B_{2}$ was taken to be $1.828 \AA$ and $99^{\circ}$ (vide infra). The displacement vectors in Figure 5 describe the motion in $\tilde{X}^{1} A_{1}$ and $\tilde{A}^{1} B_{2}$ states similar to the ground state of $\mathrm{SO}_{2}$ which has two strong $\mathrm{S}-\mathrm{O}$ covalent bonds. In both the $\tilde{X}^{1} A_{1}$ and $\tilde{A}^{1} B_{2}$ states of $\mathrm{ZrO}_{2}$, the motion is clearly symmetric $\mathrm{Zr}-\mathrm{O}$ stretch, $\mathrm{O}-\mathrm{Zr}-\mathrm{O}$ angle bend, and an antisymmetric $\mathrm{Zr}-\mathrm{O}(\mathrm{S}-\mathrm{O})$ stretch as opposed to a $\mathrm{Zr}-$ $\left(\mathrm{O}_{2}\right)$ stretch, an $\mathrm{O}-\mathrm{O}$ stretch, and a hindered rotation of the $\mathrm{O}_{2}$ group against $\mathrm{Zr}$.
The predicted spectra obtained using the methods described below are compared with the observed LIF and REMPI spectra in Figure 6. The observed spectra have not been corrected for the wavelength response of the spectrometers, so only qualitative conclusions can be drawn. The LIF and REMPI excitation spectra were predicted using Eq. (1) to calculate the energies for the $\tilde{X}^{1} A_{1}$ and $\tilde{A}^{1} B_{2}$ states and FCFs to determine the relative intensities. Details of the FCF prediction are in Appendix B. The FCFs were modeled as the product of the FCF of the two-dimensional problem described by the two $a_{1}$-symmetry mode with the FCF for the one-dimensional problem described by the $b_{2}$-asymmetry mode:

$$
\mathrm{FCF}=\left|\left\langle\boldsymbol{v}_{\mathbf{1}}^{\prime} \boldsymbol{v}_{\mathbf{2}}^{\prime} \mid \mathbf{0 0}\right\rangle\right|^{\mathbf{2}}\left|\left\langle\boldsymbol{v}^{\prime}{ }_{3} \mid \mathbf{0}\right\rangle\right|^{\mathbf{2}}
$$

The analytical expressions derived for the one-dimensional case $^{26}$ and the two-dimensional case ${ }^{27}$ were used. The expressions assume a harmonic potential. ${ }^{28}$

Normally, the strong $\tilde{A}^{1} B_{2}\left(v_{1}, v_{2}, v_{3}\right) \leftarrow \tilde{X}^{1} A_{1}(0,0$, $0)$ transitions are via the $b_{2}$-component of the electronic transition moment which restricts the transition to even quanta in $v_{3}$. Indeed, implementation of the analytical expression as described in Appendix B predicts no transitions involving odd- $v_{3}$, which is in sharp contrast to the observations (e.g., $\tilde{A}^{1} B_{2}(0,0,1) \leftarrow \tilde{X}^{1} A_{1}(0,0,0)$ band at 17562 $\left.\mathrm{cm}^{-1}\right)$. Two approaches can be used to account for the observed odd- $v_{3}$ quanta transitions: (a) allow the displacement of the $Q_{3}$ normal coordinate in the Duschinsky transformation (Appendix B) to be non-zero, as done previously for $\mathrm{TiO}_{2} ;{ }^{10}$ (b) introduce vibronic coupling as done to explain the odd$v_{3}$ quanta in $\tilde{C}^{1} B_{2} \leftarrow \tilde{X}^{1} A_{1}$ electronic transition of $\mathrm{SO}_{2} \cdot{ }^{31}$ The second approach is more realistic and is used here. In this approach the $\tilde{A}^{1} B_{2}$ state is assumed to be mixed by vibronic

(a)

A. $\widetilde{X}^{1} \mathrm{~A}_{1}$

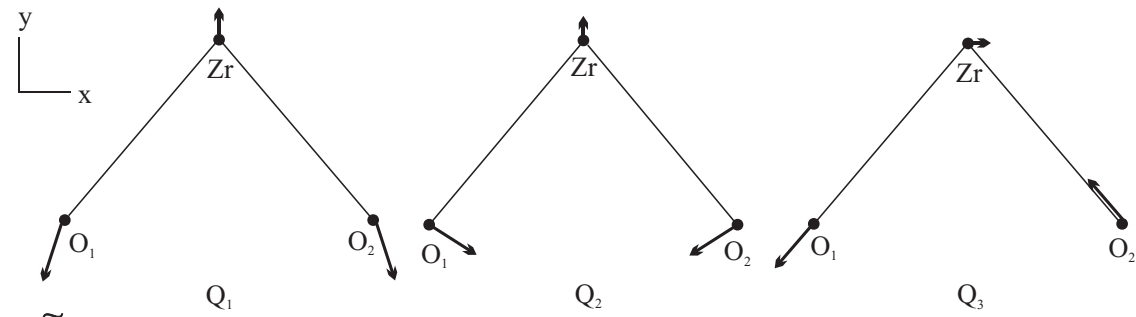

B. $\widetilde{A}^{1} \mathrm{~B}_{2}$

(b)
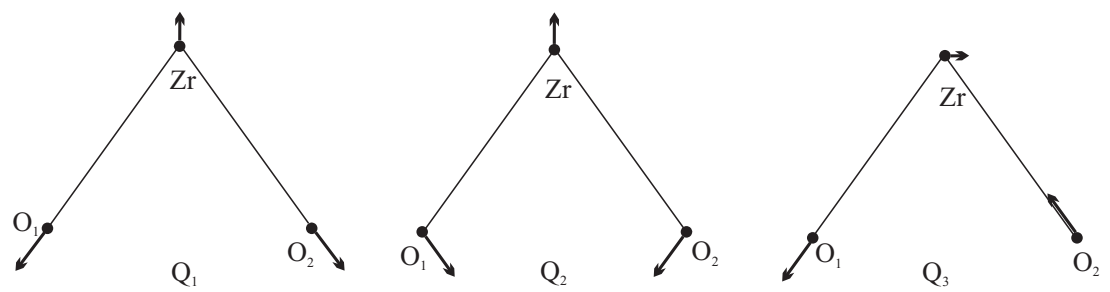

FIG. 5. Displacement vectors for the three vibrational modes of $\tilde{X}^{1} A_{1}$ state (a) and $\tilde{A}^{1} B_{2}$ state (b) determined using the experimentally derived vibrational frequencies. 


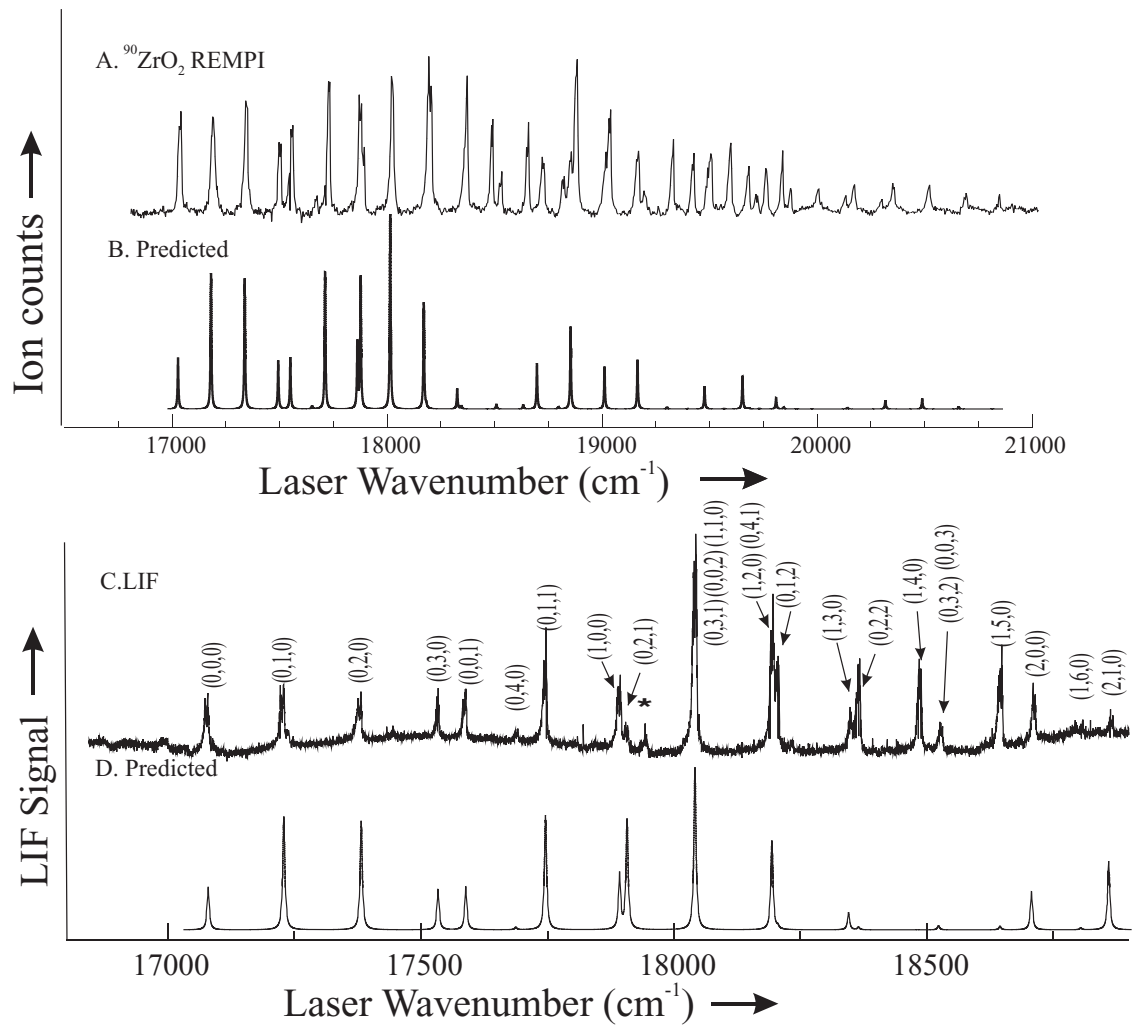

FIG. 6. Top panel: observed (a) and predicted (b) mass selected resonance enhanced multiphoton ionization (MS-REMPI) spectrum in the range of $17000 \mathrm{~cm}^{-1}-21000 \mathrm{~cm}^{-1}$ region. Bottom panel: observed (c) and predicted (d) laser induced fluorescence (LIF) spectrum in the range of $17000-18000 \mathrm{~cm}^{-1}$. The spectral feature marked with "*”" is the $C^{1} \Sigma^{+}-X^{1} \Sigma^{+}(1,0)$ transition of $\mathrm{ZrO}$.

coupling with the nearby $\tilde{B}^{1} A_{1}$ state (see Figure 4). To the first approximation the electronic wavefunction, $\Phi$, becomes

$$
\Phi_{1}\left(\tilde{A}^{1} B_{2}\right)=\Phi_{1}^{0}\left(\tilde{A}^{1} B_{2}\right)+\frac{\lambda_{21} Q_{3}}{E\left(\tilde{A}^{1} B_{2}\right)-E\left(\tilde{B}^{1} A_{1}\right)} \Phi_{2}^{0}\left(\tilde{B}^{1} A_{1}\right),
$$

where

$$
\lambda_{21} \equiv\left\langle\Phi_{2}^{0}\left(\tilde{B}^{1} A_{1}\right)\left|\left(\partial V / \partial Q_{3}\right)_{0}\right| \Phi_{1}^{0}\left(\tilde{A}^{1} B_{2}\right)\right\rangle .
$$

The square of the transition moment then becomes

$$
\begin{aligned}
& \left|\left\langle\Theta_{\mathrm{v}}\left(\tilde{A}^{1} B_{2}\right)\left|\left\langle\Phi_{1}\left(\tilde{A}^{1} B_{2}\right)|\mu| \Phi_{1}\left(\tilde{X}^{1} A_{1}\right)\right\rangle\right| \Theta_{\mathrm{v}}\left(\tilde{X}^{1} A_{1}\right)\right\rangle\right|^{2} \\
& \approx\left|\mu_{10}\right|^{2}\left|\left\langle v_{1}^{\prime} v_{2}^{\prime} \mid 00\right\rangle\right|^{2}\left|\left\langle v_{3}^{\prime} \mid 0\right\rangle\right|^{2} \\
& \quad+c\left|\mu_{20}\right|^{2}\left|\left\langle v_{1}^{\prime} v_{2}^{\prime} \mid 00\right\rangle\right|^{2}\left|\left\langle v_{3}^{\prime} \mid 1\right\rangle\right|^{2},
\end{aligned}
$$

where $\mu_{10}$ and $\mu_{20}$ are the $\tilde{A}^{1} B_{2} \leftarrow \tilde{X}^{1} A_{1}$ and $\tilde{B}^{1} A_{1}$ $\leftarrow \tilde{X}^{1} A_{1}$ electronic transition moments, respectively. The first term in Eq. (6) accounts for the transitions involving even quanta in $v_{3}$ and the second involving odd quanta. For the purpose of this prediction it is assumed that $\mu_{10}=\mu_{20}$, which is consistent with TD-DFT results. The coefficient, $c$, is given by

$$
c=\frac{1}{2}\left(\frac{\lambda_{21}}{E\left(\tilde{A}^{1} B_{2}\right)-E\left(\tilde{B}^{1} A_{1}\right)}\right)^{2} .
$$

The FCFs were predicted treating $c$ and, as mentioned above, the structure for the $\tilde{A}^{1} B_{2}$ state as variables. The opti- mized value for $c, R_{\mathrm{Zr}-\mathrm{O}}$, and $\theta$ are $1.1,1.828 \AA$, and $99^{\circ} \mathrm{ob}-$ tained from a visual comparison of the predicted and observed spectra. Given the TD-DFT/LananL2DZ calculated energies for the $\tilde{A}^{1} B_{2}\left(16753 \mathrm{~cm}^{-1}\right)$ and $\tilde{B}^{1} A_{1}\left(23724 \mathrm{~cm}^{-1}\right)$ states (i.e., $\left.\Delta E=6970 \mathrm{~cm}^{-1}\right), c$ corresponds to a vibronic coupling term, $\lambda_{21}$, of $\approx 10000 \mathrm{~cm}^{-1}$. A smaller, more realistic, value for $\lambda_{21}$ would be achieved with a smaller $\Delta E$, allowing $\mu_{20}$ to be larger than $\mu_{10}$ and/or accounting for interactions with additional states. As expected, the predicted spectrum (Figure 6) is in better agreement with the observation for the low energy portion (i.e., $<19000 \mathrm{~cm}^{-1}$ ), where vibronic coupling between the $\tilde{A}^{1} B_{2}$ and $\tilde{B}^{1} A_{1}$ states is expected to be less severe. In general, the relative intensity of combination bands is not predicted as well as overtone bands. For example, the $\tilde{A}^{1} B_{2}$ $(1,4,0) \leftarrow \tilde{X}^{1} A_{1}(0,0,0)$ band at $18476 \mathrm{~cm}^{-1}$ and the nearby overlapped $\tilde{A}^{1} B_{2}(0,0,3) \leftarrow \tilde{X}^{1} A_{1}(0,0,0)$ and $\tilde{A}^{1} B_{2}(0,3$, $2) \leftarrow \tilde{X}^{1} A_{1}(0,0,0)$ bands at $18518 \mathrm{~cm}^{-1}$. The intensities of both are underestimated, but the former is predicted to be much less intense than the latter, whereas the opposite is true.

The radiative lifetimes, $\tau$, of $\mathrm{ZrO}_{2}$ (Table III) are plotted in Figure 7 where it is evident that there are systematic trends as a function of vibrational excitation in the $\tilde{A}^{1} B_{2}$ state. Specifically, there is a strong increase in $\tau$ in the bending progression with $\tau\left(\tilde{A}^{1} B_{2}(0,0,0)\right)=0.900 \mu \mathrm{s}$ and $\tilde{A}^{1} B_{2}(0,3,0)=1.264 \mu \mathrm{s}$. One quanta of excitation of $\nu_{3}$ results in a significant increase in $\tau: \tilde{A}^{1} B_{2}(0,0,1)$ $=1.391(28) \mu \mathrm{s}$. The lifetimes decrease for levels that have a 


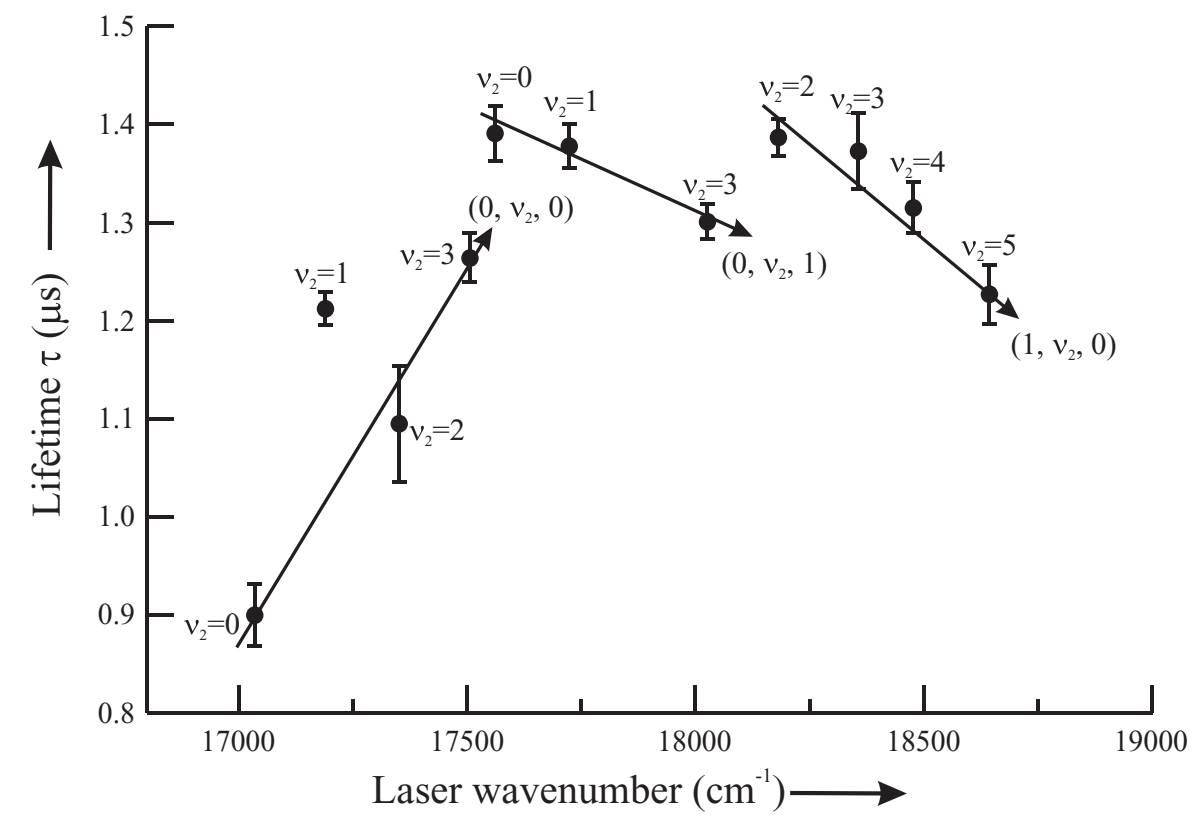

FIG. 7. The trend in fluorescence radiative lifetimes for $\tilde{A}^{1} B_{2}\left(v_{1}, v_{2}, v_{3}\right) \rightarrow \tilde{X}^{1} A_{1}(0,0,0)$ transitions of $\mathrm{ZrO}_{2}$.

combination of one quanta of excitation of either $v_{1}$ or $v_{3}$ and increasing excitation of $\nu_{2}$. The observed trends are significantly different from those observed for the $\tilde{A}^{1} B_{2}$ state of $\mathrm{TiO}_{2}$ where, for example, the $\tilde{A}^{1} B_{2}\left(0, v_{2}, 0\right)$ series decrease and the $\tilde{A}^{1} B_{2}\left(1, v_{2}, 0\right)$ increase with higher bending excitation.

\section{CONCLUSION}

Electronic transitions of $\mathrm{ZrO}_{2}$ in the visible region have been detected and analyzed. The determined vibrational frequencies for the $\tilde{A}^{1} B_{2}$ and $\tilde{X}^{1} A_{1}$ states demonstrate that there is a significant change in the bonding upon excitation. The dependence of the radiative lifetimes reflects strong vibronic coupling between the $\tilde{A}^{1} B_{2}$ and, most likely, the nearby $\tilde{B}^{1} A_{1}$ states. The LIF and MS-REMPI excitation spectra could be successfully simulated by including the vibronic coupling. There are similarities between the electronic states of $\mathrm{TiO}_{2}$, such as a significant decrease in $\omega_{2}$, a smaller bond angle, and an increase in bond length upon excitation from the $\tilde{X}^{1} A_{1}$ to the $\tilde{A}^{1} B_{2}$ state. There are also striking differences both in the vibrational dependence of the fluorescence lifetime and the observation of odd- $v_{3}$ quanta transitions in both the excitation and DLIF spectra.

Recording the high resolution LIF spectrum is in progress. The study is more difficult than that for $\mathrm{TiO}_{2}$ because of the numerous isotopologues, four of which have significant abundances. The analysis will result in a structural determination and confirmation of the vibrational assignment via the inertial defect. ${ }^{10}$ The precisely determined vibrational frequencies and term energies determined here will guide future electronic structure calculations.

\section{ACKNOWLEDGMENTS}

The work at Arizona State University was supported by grants from the Fundamental Interactions Branch, Division of Chemical Sciences, Office of Basic Energy Sciences, Department of Energy DE-FG02-01ER15153-A003), and that in Basel by the Swiss National Science Foundation (Project No. 200020-124349/1).

\section{APPENDIX A: NORMAL MODE ANALYSIS OF THE $\tilde{X}^{1} A_{1}$ AND $\tilde{A}^{1} B_{2}$ STATES}

The objective is to use experimentally derived information to simulate the LIF and MS-REMPI spectra presented in Figure 1. Evaluation of the analytical expressions used to predict the Franck-Condon factors ${ }^{29,30}$ requires relating the normal coordinates of the $\tilde{X}^{1} A_{1}$ state, $\mathbf{Q}\left(\tilde{X}^{1} A_{1}\right)$, to those of the $\tilde{A}^{1} B_{2}$ state, $\mathbf{Q}\left(\tilde{A}^{1} B_{2}\right)$, via the Duschinsky effect:

$$
\mathbf{Q}\left(\tilde{X}^{1} A_{1}\right)=\mathbf{J Q}\left(\tilde{A}^{1} B_{2}\right)+\mathbf{D} .
$$

In Eq. (A1), D is the vector of geometry displacements given in terms of the normal coordinates of the ground state $\left(=\Delta Q_{1}, \Delta Q_{2}, \Delta Q_{3}\right)$ and $J$ is the $3 \times 3$ Duschinsky rotation matrix. Both $\mathbf{J}$ and $\mathbf{D}$ are obtained from normal coordinate analyses of the $\tilde{X}^{1} A_{1}$ and $\tilde{A}^{1} B_{2}$ states.

The normal coordinate analyses was performed using the $G F$ matrix approach which is well documented by Wilson et al. ${ }^{25}$ The B matrix elements were calculated using the formula in Chapter 2-4 of Ref. 25. The experimental bond length, $R_{\mathrm{Zr}-\mathrm{O}}$ of $1.7710 \pm 0.0007 \AA$ and $\mathrm{O}-\mathrm{Zr}-\mathrm{O}$ bond angle, $\theta$, of $108.11 \pm 0.08^{\circ}$ for the $\tilde{X}^{1} A_{1}$ were taken from Ref. 4. The $R_{\mathrm{Zr}-\mathrm{O}}$ and $\theta$ for the $\tilde{A}^{1} B_{2}$ were taken to be $1.828 \AA$ and $99^{\circ}$ (vide infra). The $\mathbf{B}$ matrices for the $\tilde{X}^{1} A_{1}$ and $\tilde{A}^{1} B_{2}$ 
states are

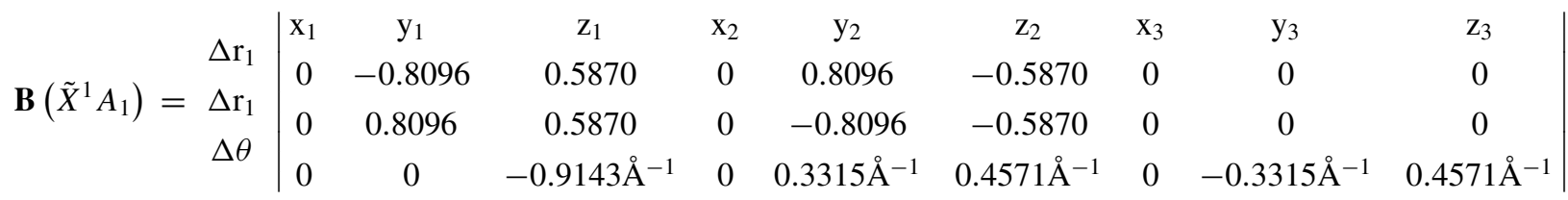

and

$$
\begin{array}{r|ccccccccc}
\Delta \mathrm{r}_{1} & \mathrm{x}_{1} & \mathrm{y}_{1} & \mathrm{z}_{1} & \mathrm{x}_{2} & \mathrm{y}_{2} & \mathrm{z}_{2} & \mathrm{x}_{3} & \mathrm{y}_{3} & \mathrm{z}_{3} \\
\mathbf{B}\left(\tilde{A}^{1} B_{2}\right)=\Delta \mathrm{r}_{1} & 0 & -0.7604 & 0.6494 & 0 & 0.7604 & -0.6494 & 0 & 0 & 0 \\
\Delta \theta & 0 & 0.7604 & 0.6494 & 0 & -0.7604 & -0.6494 & 0 & 0 & 0 \\
0 & 0 & -0.8320 \AA^{-1} & 0 & 0.3553 \AA^{-1} & 0.4160 \AA^{-1} & 0 & -0.3553 \AA^{-1} & 0.4160 \AA^{-1}
\end{array}
$$

The $\mathbf{G}$ matrix is related to the $\mathbf{B}$ matrix by $\mathbf{B} \cdot \mathbf{M}^{-1} \cdot \mathbf{B}^{\mathbf{T}}$, where $\mathbf{M}$ is the diagonal mass matrix. The $\mathbf{G}$ matrices for $\tilde{X}^{1} A_{1}$ and $\tilde{A}^{1} B_{2}$ become

$$
\mathbf{G}\left(\tilde{X}^{1} A_{1}\right)=\left|\begin{array}{ccc}
0.07364 \mathrm{amu}^{-1} & -0.003457 \mathrm{amu}^{-1} & -0.005969 \mathrm{amu}^{-1} \AA^{-1} \\
-0.003457 \mathrm{amu}^{-1} & 0.07364 \mathrm{amu}^{-1} & -0.005969 \mathrm{amu}^{-1} \AA^{-1} \\
-0.005969 \mathrm{amu}^{-1} \AA^{-1} & -0.005969 \mathrm{amu}^{-1} \AA^{-1} & 04917 \mathrm{amu}^{-1} \AA^{-2}
\end{array}\right|
$$

and

$$
\mathbf{G}\left(\tilde{A}^{1} B_{2}\right)=\left|\begin{array}{ccc}
0.07364 \mathrm{amu}^{-1} & -0.00174 \mathrm{amu}^{-1} & -0.006010 \mathrm{amu}^{-1} \AA^{-1} \\
-0.00174 \mathrm{amu}^{-1} & 0.07364 \mathrm{amu}^{-1} & -0.006010 \mathrm{amu}^{-1} \AA^{-1} \\
-0.006010 \mathrm{amu}^{-1} \AA^{-1} & -0.006010 \mathrm{amu}^{-1} \AA^{-1} & 0.04512 \mathrm{amu}^{-1} \AA^{-2}
\end{array}\right| .
$$

The three harmonic frequencies for the $\tilde{X}^{1} A_{1}$ and $\tilde{A}^{1} B_{2}$ states allow for the determination of only three of the four force constants: $f_{\mathrm{r}}, f_{\mathrm{rr}}, f_{\theta}$, and $f_{\theta \mathrm{r}}$. In the $\tilde{X}^{1} A_{1}$ state, $\omega_{1}\left(898 \mathrm{~cm}^{-1}\right) \cong \omega_{3}\left(808 \mathrm{~cm}^{-1}\right)$, so $f_{\mathrm{rr}}$ was constrained to zero. A comparison of the eigenvalues of the $G F\left(\tilde{X}^{1} A_{1}\right)$ with the observed frequencies gives

$$
\mathrm{F}\left(\tilde{X}^{1} A_{1}\right)=\left|\begin{array}{ccc}
4.9863 \operatorname{mdyn} \AA^{-1} & 0 & 1.7797 \operatorname{mdyn} \AA^{-1} \operatorname{rad}^{-1} \\
0 & 4.9863 \operatorname{mdyn} \AA^{-1} & 1.7797 \operatorname{mdyn} \AA^{-1} \operatorname{rad}^{-1} \\
1.7797 \operatorname{mdyn}^{-1} \operatorname{rad}^{-1} & 1.7797 \operatorname{mdyn} \AA^{-1} \mathrm{rad}^{-1} & 2.7351 \operatorname{mdyn}^{-2} \operatorname{rad}^{-1}
\end{array}\right| .
$$

In the $\tilde{A}^{1} B_{2}$ states, $\omega_{1}\left(819 \mathrm{~cm}^{-1}\right)$ is much greater than $\omega_{3}\left(518 \mathrm{~cm}^{-1}\right)$ and $f_{\theta \mathrm{r}}$ was constrained to zero. A comparison of the eigenvalues of the $G F\left(\tilde{A}^{1} B_{2}\right)$ with the observed frequencies gives

$$
\mathrm{F}\left(\tilde{A}^{1} B_{2}\right)=\left|\begin{array}{ccc}
3.7938 \text { mdyn } \AA^{-1} & 1.6971 \text { mdyn } \AA^{-1} & 0 \\
1.6971 \operatorname{mdyn} \AA^{-1} & 3.7938{\text { mdyn } \AA^{-1}}_{0} & 0
\end{array}\right| .
$$

The eigenvector matrices, $\mathbf{V}$, for the $\tilde{X}^{1} A_{1}$ and the $\tilde{A}^{1} B_{2}$ states are

$$
\begin{gathered}
\mathbf{V}\left(\tilde{X}^{1} A_{1}\right)=\left|\begin{array}{cccc} 
& Q_{1} & Q_{2} & Q_{3} \\
\Delta \mathrm{r}_{1} & -0.6275 & 0.3751 & 0.7071 \\
\Delta \mathrm{r}_{2} & -0.6275 & 0.3751 & 0.7071 \\
\Delta \theta & 0.4610 & 0.8477 & 0
\end{array}\right|, \\
\mathbf{V}\left(\tilde{A}^{1} B_{2}\right)=\left|\begin{array}{cccc}
\Delta \mathrm{r}_{1} & -0.7019 & 0.00467 & 0.7071 \\
\Delta \mathrm{r}_{2} & -0.7019 & 0.00467 & 0.7071 \\
\Delta \theta & 0.1213 & 0.9999 & 0
\end{array}\right| .
\end{gathered}
$$

The internal symmetry coordinates, $\mathbf{S}$, are related to the normal coordinates, $\mathbf{Q}$, by

$$
\mathbf{S}=\mathbf{L Q}
$$

where $\mathbf{L}$ and $\mathbf{V}$ differ only by a normalization constant ${ }^{29}$ chosen to assure that $\mathbf{L} \mathbf{L}^{\mathrm{T}}=\mathbf{G}$ :

$$
\mathbf{L}=\mathbf{V N}
$$

with

$$
\mathbf{N}=\left[\mathbf{V}^{-1} \mathbf{G}\left(\mathbf{V}^{\mathrm{T}}\right)^{-1}\right]^{1 / 2}
$$


The results are

$$
\begin{gathered}
\mathbf{L}\left(\tilde{X}^{1} A_{1}\right)=\left|\begin{array}{cccc} 
& Q_{1} & Q_{2} & Q_{3} \\
\Delta \mathrm{r}_{1} & -0.1688 & .08133 & 0.1963 \\
\Delta \mathrm{r}_{2} & -0.1688 & .08133 & -0.1963 \\
\Delta \theta & 0.1240 & 0.1838 & 0
\end{array}\right|, \\
\mathbf{L}\left(\tilde{A}^{1} B_{2}\right)=\left|\begin{array}{cccc} 
& Q_{1} & Q_{2} & Q_{3} \\
\Delta \mathrm{r}_{1} & -0.1896 & .00098 & 0.1941 \\
\Delta \mathrm{r}_{2} & -0.1896 & .00098 & -0.1941 \\
\Delta \theta & 0.03278 & 0.2099 & 0
\end{array}\right| .
\end{gathered}
$$

The atomic displacement matrix, $\mathbf{A A}$, is calculated by

$$
\mathbf{A A}=\mathbf{M}^{-1} \mathbf{B}^{\mathrm{T}}\left(\mathbf{L}^{-1}\right)^{\mathrm{T}},
$$

which for the $\tilde{X}^{1} A_{1}$ and the $\tilde{A}^{1} B_{2}$ states are

$$
\begin{array}{r|ccc|} 
& Q_{3} & Q_{2} & Q_{1} \\
\mathrm{y}_{\mathrm{Zr}} & 0 & 0 & -0.04586 \\
\mathrm{x}_{\mathrm{Zr}} & -0.02206 & -0.04932 & 0 \\
\mathrm{z}_{\mathrm{Zr}} & 0 & 0 & 0 \\
\mathrm{AA}\left(\tilde{X}^{1} A_{1}\right)=\mathrm{y}_{02} & 0.1614 & -0.07218 & 0.1289 \\
\mathrm{x}_{02} & 0.06200 & 0.1386 & -0.09346 \\
\mathrm{z}_{02} & 0 & 0 & 0 \\
\mathrm{y}_{01} & -0.1614 & 0.07218 & 0.1289 \\
\mathrm{x}_{01} & 0.06200 & 0.1386 & 0.09346 \\
\mathrm{z}_{01} & 0 & 0 & 0
\end{array}
$$

and

$$
\begin{array}{r|ccc|} 
& Q_{3} & Q_{2} & Q_{1} \\
\mathrm{y}_{\mathrm{Zr}} & 0 & 0 & -0.04356 \\
\mathrm{x}_{\mathrm{Zr}} & -0.03811 & -0.03829 & 0 \\
\mathrm{z}_{\mathrm{Zr}} & 0 & 0 & 0 \\
\mathrm{y}_{02} & 0.1253 & -0.1247 & 0.1224 \\
\mathrm{x}_{02} & 0.1071 & -0.1076 & -0.1045 \\
\mathrm{z}_{02} & 0 & 0 & 0 \\
\mathrm{y}_{01} & -0.1253 & -0.1247 & 0.1224 \\
\mathrm{x}_{01} & 0.1071 & -0.1076 & 0.1046 \\
\mathrm{z}_{01} & 0 & 0 & 0
\end{array}
$$

\section{APPENDIX B: FRANCK-CONDON FACTORS}

The $3 \times 3$ Duschinsky rotation matrix, $\mathbf{J}$, is given by ${ }^{30}$

$$
\mathbf{J}=\left(\mathbf{L}\left(\tilde{A}^{1} B_{2}\right) \mathbf{B}\left(\tilde{A}^{1} B_{2}\right)\right) \mathbf{M}^{-1}\left(\left(\mathbf{L}\left(\tilde{X}^{1} A_{1}\right)\right)^{-1} \mathbf{B}\left(\tilde{X}^{1} A_{1}\right)\right)^{T} .
$$

Substitution of Eqs. (A2), (A3), (A12), and (A13) into Eq. (B1) gives the Duschinsky rotation matrix:

$$
\mathbf{J}=\left|\begin{array}{ccc}
0.9350 & 0.3546 & 0 \\
-0.3546 & 0.9350 & 0 \\
0 & 0 & 0.9971
\end{array}\right| .
$$

$\mathbf{J}$ is a block diagonal due to the $C_{2 v}$ symmetry and the FCF problem separates into a two-dimensional problem for the two $a_{1}$ modes and a one-dimensional problem for the $b_{2}$ mode. Interestingly, $\mathbf{J}_{33}$ is not unity implying that the $v_{3}$ vibrational mode couples with rotation about the $c$-principal axis, both having $b_{2}$ symmetry. ${ }^{27}$

The Duschinsky displacement vector, $\mathbf{D}$, is given by ${ }^{30}$

$$
\mathbf{D}=\left(\mathbf{L}\left(\tilde{A}^{1} B_{2}\right) \mathbf{B}\left(\tilde{A}^{1} B_{2}\right)\right)^{-1}\left(\mathbf{R}_{\mathrm{eq}}\left(\tilde{A}^{1} B_{2}\right)-\mathbf{R}_{\mathrm{eq}}\left(\tilde{X}^{1} A_{1}\right)\right),
$$

where $\mathbf{R}_{\mathrm{eq}}$ is the $9 \times 1$ vector of equilibrium Cartesian center of mass coordinates. $\mathbf{R}_{\mathrm{eq}}\left(\tilde{X}^{1} A_{1}\right)$ is the obtained experimental structure $\left(1.771 \AA\right.$ and $\left.108.11^{\circ}\right){ }^{4}$ Initially, $R_{e q}\left(\tilde{A}^{1} B_{2}\right)$ was obtained from the $a b$ initio predicted structure in Table IV (i.e., $1.843 \AA$ and $101.8^{\circ}$ ). The structure was varied to reproduce the observed intensities with the final optimized structure being $1.828 \AA$ and $99^{\circ}$. The $\mathbf{D}$ vector becomes

$$
\mathbf{D}=\left(\begin{array}{c}
0.5185 \\
0.5535 \\
0
\end{array}\right)
$$

$\mathbf{J}, \mathbf{D}$, and the experimentally determined harmonic frequencies are used as an input to the analytical expressions for FCFs (Refs. 26 and 27) derived under the assumption that the $\tilde{A}^{1} B_{2}$ and $\tilde{X}^{1} A_{1}$ state potentials can be modeled as two displaced and distorted harmonic oscillators.

${ }^{1}$ Y. Gong, M. Zhou, and L. Andrews, Chem. Rev. 109, 6765 (2009).

${ }^{2}$ M. Kaufman, J. Meunter, and W. Klemperer, J. Chem. Phys. 47, 3365 (1967).

${ }^{3}$ G. V. Chertihin and L. Andrews, J. Phys. Chem. 97, 6356 (1995).

${ }^{4}$ D. J. Burgh, R. D. Seunram, and W. J. Stevens, J. Phys. Chem. 111, 3526 (1999).

${ }^{5}$ O. C Thomas, S. Xu, T. P. Lippa, and K. H Bowen, J. Cluster Sci. 10(4), 525 (1999).

${ }^{6}$ W. Zheng, K. H. Bowen, Jr., J. Li, I. Dąbkowska, and M. Gutowski, J. Phys. Chem. A 109, 11521 (2005).

${ }^{7}$ D. K. W. Mok, F. Chau, J. M. Dyke, and E. P. F. Lee, Chem. Phys. Lett. 458, 11 (2008).

${ }^{8}$ S. Li and D. A. Dixon, J. Phys. Chem. A 114, 2665 (2010).

${ }^{9}$ H. Wang, T. C. Steimle, C. Apetrei, and J. P. Maier, Phys. Chem. Chem. Phys. 11, 2649 (2009).

${ }^{10}$ X. Zhuang, A. Le, T. C. Steimle, R. Nagarajan, V. Gupta, and J. P. Maier, Phys. Chem. Chem. Phys. 12, 15018 (2010).

${ }^{11}$ A. E. Boguslavskiy and J. P. Maier, Phys. Chem. Chem. Phys. 9, 127 (2007).

${ }^{12}$ W. C. Wiley and I. H. McLaren, Rev. Sci. Instrum. 26, 1150 (1955).

${ }^{13}$ E. Murad and D. L. Hildenbrand, J. Chem. Phys. 63, 1133 (1975).

${ }^{14}$ P. J. Hay and W. R. Wadt, J. Chem. Phys. 82, 270 (1985).

${ }^{15}$ W. J. Stevens, H. Basch, and M. Krauss, J. Chem. Phys. 81, 6026 (1984).

${ }^{16}$ W. J. Stevens, M. Krauss, H. Basch, and P. G. Jasien, Can. J. Chem. 70, 612 (1992).

${ }^{17}$ F. Grein, J. Chem. Phys. 126, 034313 (2007).

${ }^{18}$ M. J. Frisch, G. W. Trucks, H. B. Schlegel et al., GAUSSIAN 09, Revision A.02, Gaussian, Inc., Wallingford, CT, 2009.

${ }^{19}$ MOLPRO, a package of ab initio programs designed by H.-J. Werner and P. J. Knowles, version 2006.1, R. Lindh, F. R. Manby, M. Schütz et al. 
${ }^{20}$ B. Simard, S. A. Mitchell, M. R. Humpries, and P. A. Hackett, J. Mol. Spectrosc. 129, 186 (1988).

${ }^{21}$ See supplementary material at http://dx.doi.org/10.1063/1.3632053 for three pages of observed and calculated levels for $\tilde{X}^{1} A_{1}$ ground state of $\mathrm{ZrO}_{2}$.

${ }^{22}$ G. Herzberg, Molecular Spectra and Molecular Structure. III. Electronic Spectra and Electronic Structure of Polyatomic Molecules (Kreiger, Malabar, 1991).

${ }^{23}$ L. Seidner, G. Stock, A. L. Sobolewski, and W. Domcke, J. Chem. Phys. 96, 5298 (1992).

${ }^{24}$ C.-K. Lin, M.-C. Li, M. Yamaki, M. Hayashi, and S. H. Lin, Phys. Chem. Chem. Phys. 12, 11432 (2010).
${ }^{25}$ E. B. Wilson, Jr., J. C. Decius, and P. C. Cross, Molecular Vibrations (McGraw-Hill, New York, 1955).

${ }^{26}$ J. L. Chang, J. Mol. Spectrosc. 232, 102 (2005).

${ }^{27}$ J. L. Chang, J. Chem. Phys. 128, 174111 (2008).

${ }^{28}$ T. E. Sharp and H. M. Rosenstock, J. Chem. Phys. 41, 3453 (1964).

${ }^{29}$ G. L. Goodman and J. Berkowitz, in Molecular Ions, edited by J. Berkowitz and K. O. Groenveld (Plenum, New York, 1983), p. 69.

${ }^{30} \mathrm{P}$. Chen, in Unimolecular and Bimolecular Reaction Dynamics, edited by C. Y. Ng, T. Baer, and I. Powis (Wiley, New York, 1994), Vol. 3, p. 372.

${ }^{31}$ P. C. Ray, M. F. Arendt, and L. J. Butler, J. Chem. Phys. 109, 13 (1998) 